\title{
Sigamos compartiendo
}

\section{Let's keep sharing}

\section{Dr. Carlos de Jesús Álvarez-Díaz*}

A I finalizar el año, época en que todo el mundo desea obsequiar algo y desear parabienes, para los integrantes del Comité Editorial significa todo un año de esfuerzo, entregando nuestro ánimo y conocimiento para que todo resulte como cabe esperar.

En este número, presentamos una interesante investigación sobre los métodos utilizados en la reconstrucción de secuelas de heridas complejas en la pierna y otra más sobre complicaciones en pacientes operados de reducción de fracturas NOE. La primera en un lapso de tres años y la segunda en ocho años. En la sección de casos clínicos, tenemos nuevamente los problemas que se presentan con el uso de rellenos faciales, en el que se analizan sus reacciones adversas. Asimismo, presentamos un clásico del armamentario de nuestra especialidad, con la utilidad de la zetaplastia en las secuelas por quemaduras, y otro más que describe la manera de corregir las secuelas de quemadura eléctrica por alto voltaje en las extremidades y, por último, otro clásico, la reconstrucción nasal por medio del colgajo frontal en un niño.

Para nosotros es un privilegio presentarles estos trabajos que muestran la productividad de nuestros cirujanos plásticos y, desde el punto de vista de los objetivos que planeamos desde los inicios de esta revista, comunicar y difundir nuestra experiencia en la práctica clínica quirúrgica cotidiana, y con ello promover la educación médica continua, ya que lo escrito queda plasmado ad aeternum.

Continuamos invitando a nuestros lectores a que nos envíen sus trabajos para que sigamos compartiéndolos.

Correspondencia:

Dr. Carlos de Jesús Álvarez Díaz

E-mail: cajealdi@gmail.com 